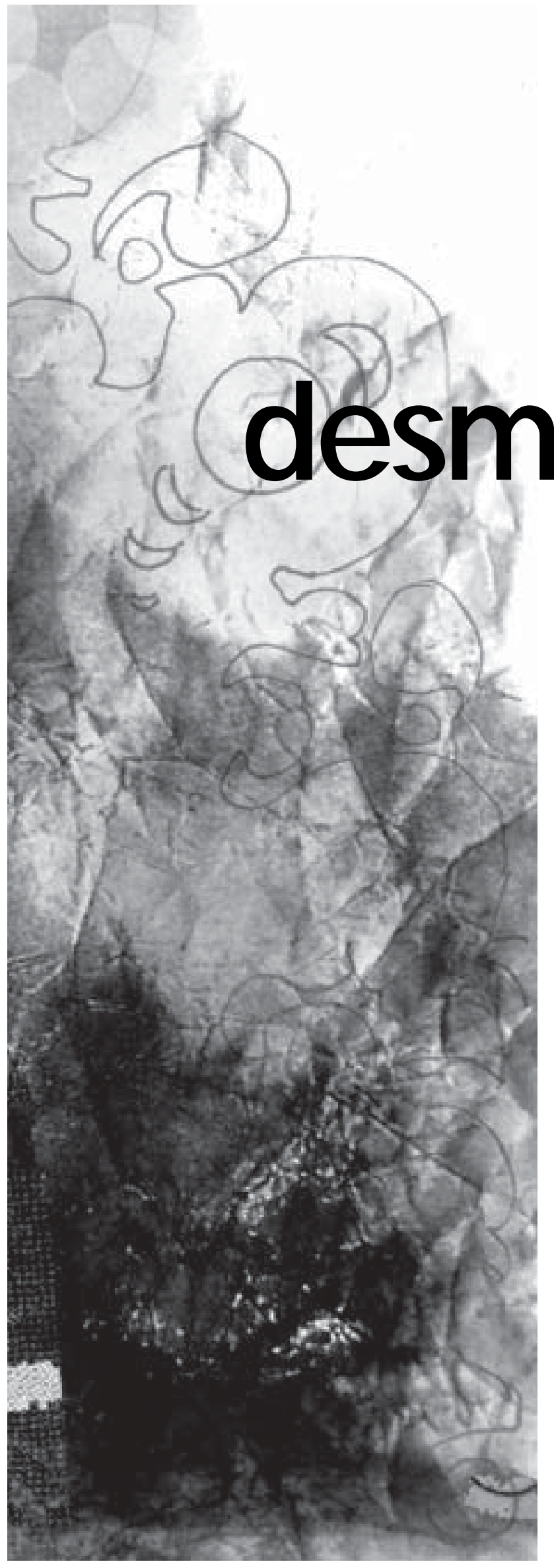

\title{
La unión
} antelada ${ }^{1}$

J osé Hleap B. (johleap@yahoo.com)

Profesor Titular (estudiante de Doctorado en educación)

Escuela de Comunicación Social, Facultad de Artes Integradas, Universidad del Valle.

\section{RESUMEN}

Utilizando como pre-texto un capítulo de «Amor liquido» de Bauman(2007), en este artículo se presentan las consecuencias locales que para los vínculos sociales ( y humanos) tiene el ejercicio de una «economía política del miedo», del unanimismo globalizado, agenciada eficazmente por los nuevos gurús de la esfera pública mediática. Aborda también la existencia de estrategias sociales (de movimientos, comunidades 0 activistas) que redefinen la relación entre lo global y lo local, al asumirla como la existencia de diferentes escalas en las que se juegan las redes para el establecimiento de coaliciones con otras luchas basadas en lógicas situadas. Así, el escenario se hace más complejo y las opciones para el comunicador social se ubican en los campos éticos y políticos de su quehacer.

\section{PALABRAS CLAVE}

Convivencia, economía política del miedo, aprendizaje social de la ciudadanía, incomunicación 
En la sociedad espectacular es la misma comunicabilidad, la misma esencia genérica (esto es, el lenguaje) lo que acaba separado en una esfera autónoma. Lo que impide la comunicación es la comunicabilidad misma, los hombres están separados por aquello que los une. Los periodistas y los mediócratas son el nuevo clero de esta alienación de la naturaleza lingüística del hombre.

Giogio Agamben (2006)

ntroducción

El cuarto capítulo de «Amor Líquido» de Zygmunt Bauman (2007), la unión desmantelada, no es un capitulo en términos convencionales porque el libro tampoco lo es: se trata, como lo indica el propio autor, de un «fotomontaje» cuyo «efecto de composición» es «una tarea inconclusa, que los lectores deberán completar» (2007:8). Si el libro «procura desentrañar, registrar y entender esa extraña fragilidad de los vínculos humanos, el sentimiento de inseguridad que esa fragilidad inspira y los deseos conflictivos que ese sentimiento despierta, provocando el impulso de estrechar los lazos, pero manteniéndolos al mismo tiempo flojos para poder desanudarlos»(2007:8), la «unión desmantelada» se ocupa de «los desechos humanos», que serían las víctimas propiciatorias para «los temores y ansiedades igualmente ubicuos de la precariedad de la vida moderna»(2007:160), operando como límites, pues no alcanzan a ser «otros», de esos «vínculos humanos»: los inmigrantes, los desplazados, los refugiados.

Notificado por el autor, la lectura que presento en este articulo no pretende sintetizar lo expuesto si no exponer lo que me dio a pensar, en medio de la investigación «el conocimiento social en convivencia como vía para la construcción de culturas de paz»: El lugar de la «vida cotidiana» y las «políticas públicas» cuando a duras penas se sobrevive «día a día en la inmediatez del momento», cuando no se tiene un lugar ni una identidad «positiva». Esta aproximación denuncia así toda nuestra obstinación de «modernidad capitalista» por ubicar en un tiempo (en su sucesión lineal), en un espacio (en su desagregación institucional) y en una identidad (cosificada) al otro de la vida cotidiana y de la vida pública (en su interesada separación), como arsenal teórico-político para la administración de la vida (incluso de la «propia» vida), para el ejercicio del bio-poder, mediante «identidades tuteladas» que salven el «complejo de soberanía arraigado en la unión de territorio-nación y estado» (2007:196). Este acercamiento además pronuncia la operación mediante la cual se logra la inclusión, el «reconocimiento» de la ciudadanía de estos «desechos humanos», al precio de construir su desnudez natal, de excluir, de borrar todo vestigio de previa humanidad, de derechos y vida digna, para arroparlos con «los arneses juridico-legales», con los «valores» de una «cultura ciudadana» construida a la medida de «la diabólica trinidad de territorio-estado-nación. Esta aproximación también anuncia «la comunidad que viene» (asumiendo el título del libro de Agamben), la «permanencia en lo efímero» de esta «modernidad liquida», con todas sus consecuencias. 


\section{La producción de sobrantes humanos}

Bauman señala como existen dos ramas de la industria moderna que han producido y producen «sobrantes humanos»: En «la producción y reproducción del orden social» desde donde se recortan, se segregan o se extirpan «aquellas partes de la materia prima humana que demuestren ser ineptas para ese orden» (2007:161) como sobrantes indeseables y/ o inútiles. La otra rama es la del progreso económico que «exige la invalidación, el desmantelamiento y la eventual aniquilación de ciertos modos de vida y de subsistencia del ser humano, ya que no pueden ni podrían alcanzar los crecientes estándares de productividad y rentabilidad» (2007:161). Otra rama de la industria moderna, la de eliminación de desechos, se hace cargo de los sobrantes «transformando en basurales grandes sectores del planeta» (¿La invención del «tercer mundo»?) o reciclando y descontaminando aquellos sobrantes que se sometan a su «civilidad». Sin embargo, la expansión planetaria del modo de vida moderno y la abundancia de sobrantes han llevado esta industria a la crisis, al punto en el cual «el mundo en su totalidad se está convirtiendo en una tierra fronteriza planetaria» (2007:175), fabrica de desplazamiento y planta recicladora de desplazados.

Si bien «el detrimento humano resultante del afán y el celo por incluir/ excluir -disparados y sistemáticamente reafirmados por el principio y las prácticas de la trinidad territorio-nación-estadoha logrado ser minimizado hasta considerárselo más una molestia curable y transitoria que una ominosa señal de catástrofe inminente»(2007:174), ya no existen territorios «seguros», libres de «desechos» y la sensación de precariedad reinante (nacida de «la inseguridad de la propia posición social entremezclada con la incertidumbre aguda acerca del futuro de los medios de subsistencia») es conducida, mediante la «economía política del miedo»(U. Beck), hacia el temor por la seguridad personal, la xenofobia y el racismo, al punto en el que «culpar a los inmigrantes -los extranjeros, los recién llegados, en especial los extranjeros recién llegados- del malestar social en todos sus aspectos (y en primer lugar de la nauseabunda y paralizante sensación de inseguridad) se va transformando poco a poco en habito global»(2007:158). Aunque es una reflexión marcada por la presente situación Europea, la tendencia mundial cobra en nuestro País y en la ciudad de Cali, una actualidad macabra: No son solo los desplazados de las violencias armadas, o los inmigrantes económicos locales, es la creciente estigmatización de pobladores que por su color de piel y/o su origen social y lugar de habitación son «los sospechosos de siempre», los señalados causantes de todos los males.

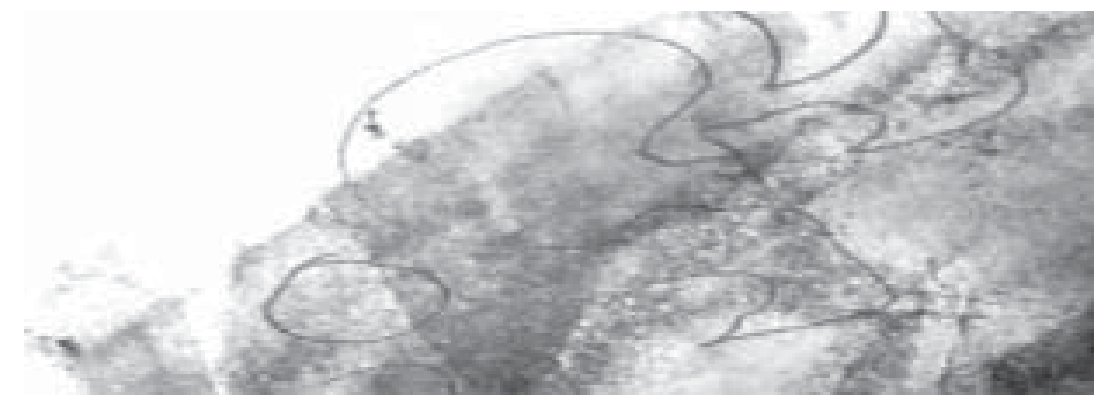

Como ha planteado Agamben (2006), es la comunicabilidad, el régimen de pensamiento único agenciado por periodistas y mediócratas, el que paulatinamente ha secuestrado la comunicación social, constriñéndonos a nombrar en sus términos al otro, al diferente: es el terrorista. El ejercicio de esa economía política del miedo (sea en la versión internacional de «lucha contra el terrorismo» o en la nacional de «seguridad democrática» o en la paranoia local de la «ola negra» que se tomó la ciudad) nos hace desear la seguridad (que ya tiene sus solícitos regentes) y el gobierno fuerte, así sea necesario desmantelar no sólo nuestra precaria «democracia», sino incluso las formas más desinteresadas de vínculo humano (la solidaridad, la cooperación, el afecto...), como se ha visto en el actual estado de paranoia mundial con la «gripa porcina».

Resulta profundamente esclarecedor para los que intentamos comprender la convivencia en condiciones de desigualdad, exclusión y segregación socio-espacial la aclaración que hace Bauman sobre esta soberanía que «decide el valor o no valor de la vida», al plantear "que esto es así solamente y en la medida en que la trinidad territorio-estadopoblación ha sido elevada al rango de principio universal de cohabitación humana, impuesto y determinado a ser impuesto hasta en el último rincón del planeta, incluso en las regiones que durante siglos no han logrado alcanzar las condiciones más elementales de dicha trinidad (a saber, la homogeneidad poblacional y/o el asentamiento permanente que conduce al arraigo)» (2007:173). 


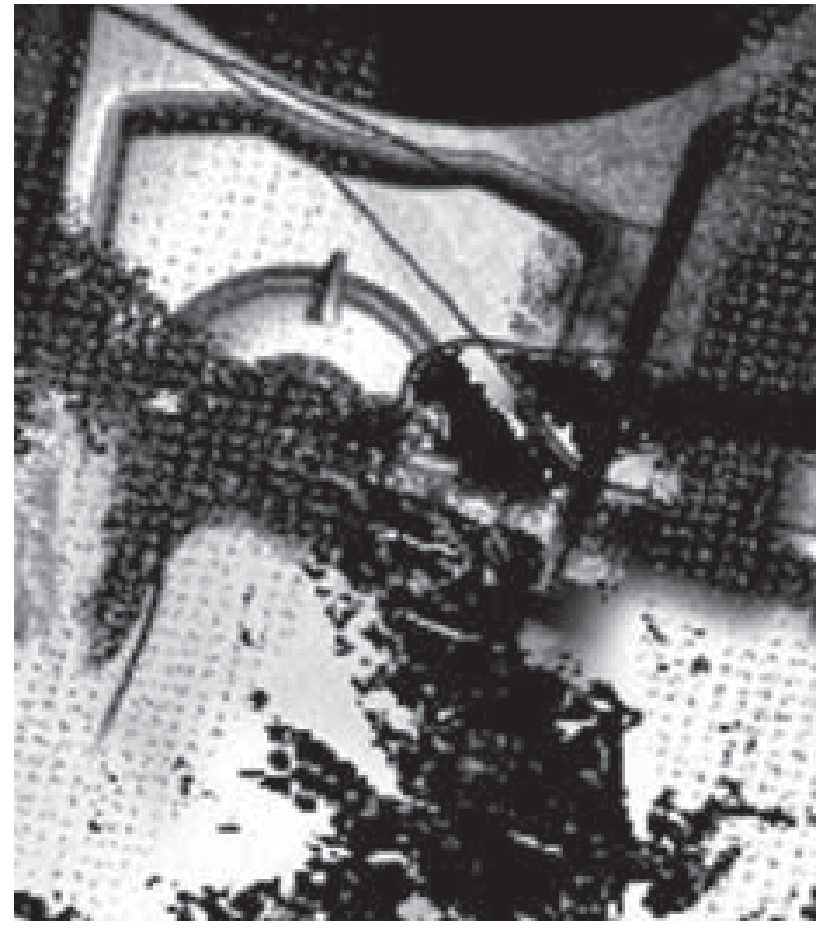

Así como Bauman describe la extraterritorialidad de los nuevos «hiperguetos» (los campos de refugiados o desplazados) como «agrupamientos truncos, artificiales, y ostensiblemente incompletos, son conglomerados y no comunidades. Son condensaciones topográficas incapaces de subsistir por su propia cuenta» (2007:187), podríamos hablar de la subterritorialidad de las «invasiones» urbanas que, contrariamente, hacen de la precariedad el fundamento de la vida en común, guerreándose su lugar en la ciudad: los guetos actuales para los desechos humanos de nuestras ciudades.

Una mirada rápida a las noticias sobre la ciudad que ocupan la primera plana de los noticieros (nacionales y locales) nos permite dibujar un escenario para los pobladores, caracterizado por la indolencia con lo público, la voracidad arrasadora del interés privado y la criminalidad campeante, especialmente en los sectores populares. Cuando nos hemos apartado de la mirada mediática y logramos conocer la realidad cotidiana de «asentamientos subnormales» señalados por las mediciones de delitos como «ollas», encontramos en las luchas por sobrevivir (ni siquiera por buscar una vida digna) en la ciudad el aporte cotidiano a la convivencia social de las particulares formas de relación entre los señalados «desechos humanos» y de ellos con la ciudad, así como la memoria -borrada institucionalmente- de su aporte en los distintos proyectos y experiencias de intervención, borrón que refuerza las representaciones violentas con las que los mismos habitantes de estas ciudades terminan identificándose.

\section{Las Políticas públicas.}

Ubicados en la orilla del conocimiento ordinario sobre la ciudadanía, ${ }^{2}$ nos preguntamos por los recursos culturales a los que recurren los sujetos para hacerse un lugar (en el sentido de De Certeau) en la ciudad, constituir su sentido de ciudadanía. Se trata entonces de privilegiar el saber de las prácticas, una «poética de las relaciones sociales» en donde la creatividad ${ }^{3}$, las astucias, la lógica de la oportunidad, las tácticas ${ }^{4}$ de los actores sociales, prevalecen sobre la categorización que los expertos y reconocer y potenciar este saber mediante una interlocución sistemática entre saberes diferentes $\mathrm{y} / \mathrm{o}$ desigualmente constituidos, en un marco de aprendizaje social de la ciudadanía, donde emerge una idea de la convivencia y de gestación y defensa de lo público que politiza la cotidianeidad urbana y pluraliza la «cultura ciudadana». Se parte de la idea de que lo político se cristaliza en las prácticas y elecciones de la vida 'ordinaria', en donde la ciudadanía es un concepto dinámico y no solamente el resultado exclusivo de la acción del Estado, por cuanto la visión institucional de ciudadanía es transformada constantemente por procesos de producción, circulación y empleo estratégico y táctico de conocimientos socialmente pertinentes para reinventar la convivencia y el bienestar social. Dichos procesos dan como resultado la coexistencia de varias ciudadanías entrelazadas y en constante negociación que se mueven entre perspectivas institucionales, y expectativas y luchas individuales y colectivas. Así, la generación de políticas públicas sobre convivencia se ubica en el caldero de los conflictos sociales que caracterizan la vida urbana.

Nos apartamos entonces de las concepciones de convivencia propias del liberalismo, del republicanismo cívico y del de «redes de apoyo social». La «convivencia» pensada como resolución pacífica de conflictos bajo el presupuesto de una relación entre individuos autónomos y racionales, construcción propia de un tipo de cultura y de una propuesta política de sociedad (tanto del liberalismo como del republicanismo cívico), resulta incapaz de asumir la alteridad como diversidad de intereses y puntos de vista no conciliables por la apelación a 
un orden superior (Ilámese Dios, Estado o Razón) ante el cual las diferencias o desaparecen 0 resultan secundarias. La «convivencia» entendida como «redes de apoyo social», por tratar de resaltar la dimensión conjuntista, solidaria, de las relaciones humanas, se convierte en la otra cara de la moneda de la violencia, al no asumir que el carácter conflictivo del vivir juntos no lo hace necesariamente violento y al idealizar la convivencia situada que busca "comprender», dando por sentado la existencia de UN fenómeno llamado «Violencia», enfatizando la «cultura de la violencia» que genera unos actores violentos y que se alimenta en «la vida cotidiana, en algunas actuaciones de los funcionarios institucionales y en los medios de comunicación» pero que no se pregunta, como propone Habermas (2003:66), por «la violencia estructural, y en cierto sentido habitual, de la ofensiva desigualdad social y de la degradante discriminación», por «la violencia del empobrecimiento y de la marginalización» que hace que «nuestras relaciones sociales están atravesadas por violencia, acción estratégica y manipulación».

\section{La comunidad que viene.}

Bauman advierte que la extraterritorialidad de los hiperguetos hace de los refugiados «una caricatura de la nueva elite del poder del mundo globalizado» (2007:179) y reciben «el temor y el resentimiento popular» dirigido a «esa elite global que flota más allá del alcance del control humano, y a la que nadie puede hacerle frente, dado el enorme poder del que dispone» (2007:180). Ambas condiciones de la extraterritorialidad serían «los laboratorios donde se experimenta bajo condiciones extremas con la desemantización del espacio, la fragilidad y desechabilidad de los significados, la indeterminación y plasticidad de las identidades $y$, por sobre todas las cosas, con la nueva permanencia de lo efímero, todas ellas tendencias constitutivas de la fase líquida de la modernidad, testeadas allí del mismo modo como fueron testeados los límites de la maleabilidad y sumisión humanas y los mecanismos para llegar a esos límites en los campos de concentración de la etapa sólida de la historia moderna»(2007:184). Podríamos asumir que el actual desmantelamiento de «derechos humanos», así como la puesta en cuarentena de los vínculos humanos (solidaridad, compañerismo, afecto) aplicados a poblaciones específicas (los presos de Abu Ghraib y Guantanamo, los Mexicanos de la gripa porcina, los «desechables» de las ciudades) anuncian «la comunidad que viene», de conservar la tendencia desocializante propiciada por la economía política del miedo.

No obstante, es preciso no llamarse a engaños: antes que dibujar el destino sórdido de toda la humanidad, estos «laboratorios» de la sociabilidad por venir presentan «extremos opuestos del proceso de globalización» en los que se muestra la arquitectura profundamente asimétrica de esa modernidad liquida, donde la «condición humana» no se define, como propone Bauman, en una "comunidad global imaginada», en la que la pertenencia a la «especie humana» esté por encima de cualquier otro tipo de pertenencia particular, puesto que el «globalitarismo» (Bauman, 2004:287) precisa las «competencias» desde las cuales se es «humano» o desechable. Aunque el autor afirma recurrentemente en su libro que no existen soluciones locales para problemas globales, es necesario afirmar, con De Sousa Santos (2002:170), que existen distintas globalizaciones: «el sistema-mundo es una red de globalismos localizados y de localismos globalizados» y en cada una de sus articulaciones se juega de cierta manera lo local y lo global; por eso es que Bauman puede reivindicar la ciudad como «terreno de investigación donde experimentar, probar $y$, eventualmente aplicar los medios para aplacar y erradicar esa incertidumbre y esa inseguridad»(2007: 153).

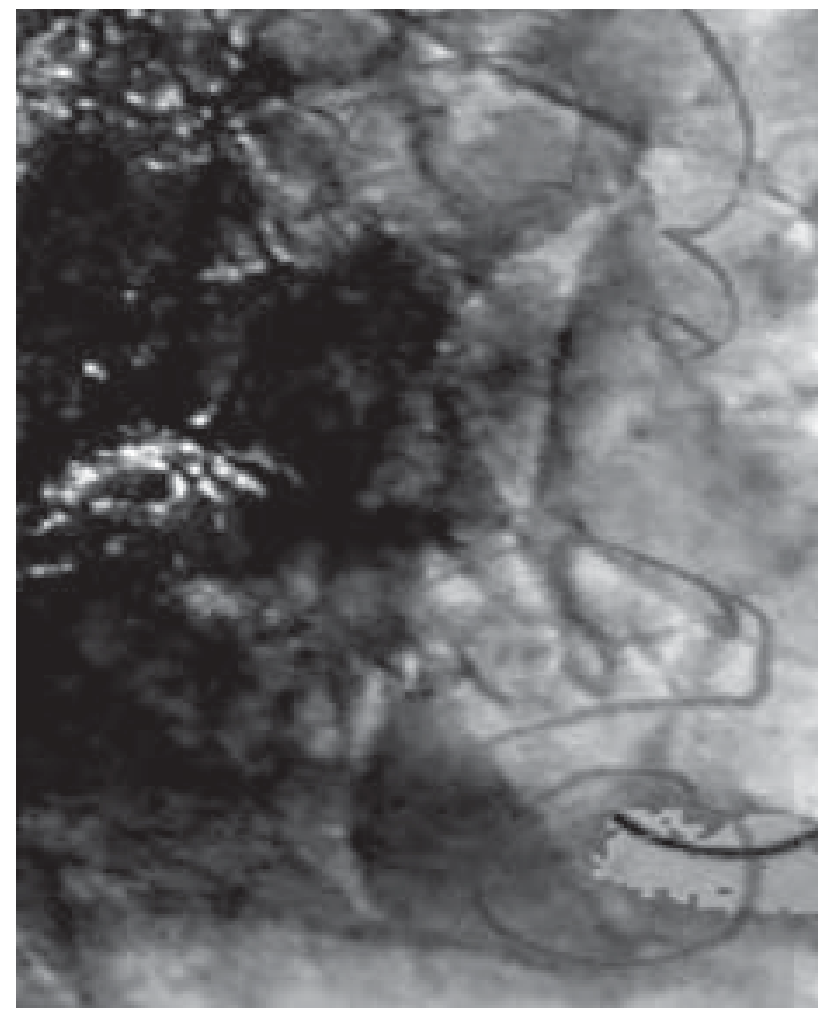




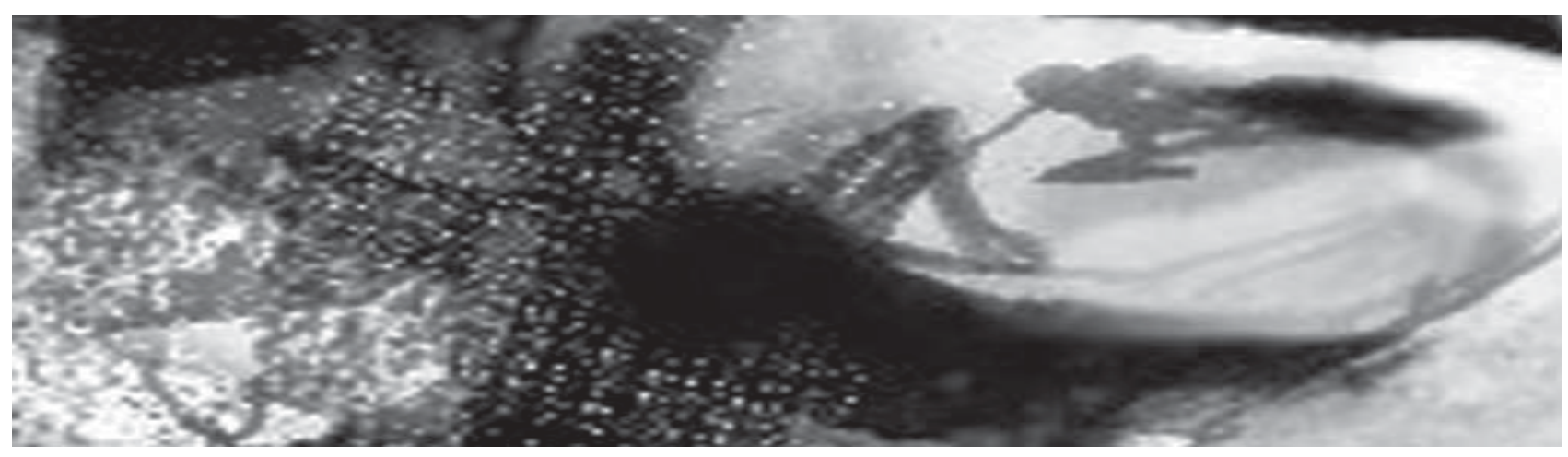

La tendencia de cierta globalización a reducir los espacios y modos de acción pública al referente del mercado y a la administración gerencial de la población (Muller, 2006) son una cara del proceso que en su reverso tiene las «lógicas de lugar» (Escobar, 2005:170), 0 localización, como estrategias sociales (de movimientos sociales, comunidades 0 activistas) que redefinen la relación entre lo global y lo local, al asumirla como la existencia de diferentes escalas en las que se juegan las redes para el establecimiento de coaliciones con otras luchas basadas-en -lugar. (2005: 182). Desde esta perspectiva, las organizaciones sociales (no los ciudadanos abstractos) actúan sobre las políticas públicas de localización global del capitalismo tardío, con una triple estrategia: «Una estrategia localizante basada en el lugar, para la defensa de los modelos locales de naturaleza y prácticas culturales; una estrategia de localización a través de un activo y creativo engranaje con las fuerzas translocales, tales como movimientos ambientales o de identidad o varias coaliciones globales en contra de la globalización y el libre mercado; y una dinámica estrategia política que vincula la identidad, el territorio y la cultura en niveles locales, regionales, nacionales y transnacionales»(Escobar, 2005:184). El escenario, así dibujado, muestra más actores, conflictos y modos de acción que el esbozado por la mirada centrada en la «gobernancia» de la «pequeña burguesía planetaria»(Agamben, 2006:54), cuya preocupación más sensible estriba en que «entre las restricciones ligadas al contexto exterior que cada vez más claramente determinan el contenido de las políticas públicas y las demandas de nuevas formas de participación política, los responsables políticos deberán encontrar nuevos modos de transacción, so pena de ver desarrollarse las diferentes formas de populismo portadoras de visiones del mundo a la vez simplistas y peligrosas»(Muller, 2006: 164).

\section{La in-comunicación.}

Confiados - y confinados- en una profesionalización que neutraliza los dilemas éticos y políticos de su ejercicio, los comunicadores sociales practican con total despreocupación, como agentes de la producción inmaterial de la sociedad (su 'materia prima' de trabajo es la producción de conocimientos, de vínculos sociales, de afectos), una modulación (Deleuze) de la multiplicidad comprometida con el unanimismo de la economía política del miedo,

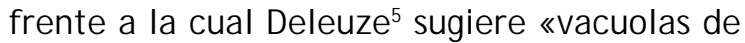
incomunicación». La in-comunicación propuesta, esa que apela a la creatividad, no es la del aislamiento y des-unión que propicia la lógica desmanteladora del globalitarismo (Bauman), pues el solipsismo es la opción más adecuada y deseable para la tendencia hegemónica; la incomunicación es aquella que atenta contra la comunicabilidad como esfera autónoma y ubicua, que es la que según Agamben impide la comunicación, mercancía espectacular que procede de la expropiación de la sociabilidad humana. En el mundo del pensamiento único, es la proliferación de otros saberes, otras voces, otros relatos, otras experiencias -incomunicables para la comunicabilidad mediática- la que le da sentido (ético y político) a la comunicación social. 
${ }^{1}$ Este artículo hace parte del trabajo conceptual abordado en la investigación «El conocimiento social en convivencia como vía para la construcción de culturas de paz», financiado por Colciencias y de la interlocución sobre políticas públicas en convivencia sostenida con Carlos Arango Calad.

${ }^{2}$ Al respecto Michel Maffesoli (1993) ha desarrollado una crítica a la formalización experta sociológica de las dinámicas sociales en «El conocimiento ordinario».

${ }^{3}$ Cabe aquí recordar el pensamiento de Cornelius Castoriadis en donde la creación tiene relación directa con la valorización y potenciación de la tradición en su interacción dinámica con el presente y con las diferencias sustantivas que constituyen la sociedad: «No habrá transformación social radical, nueva sociedad, sociedad autónoma, más que por y en una nueva conciencia histórica, que a la vez implique una restauración del valor de la tradición y otra actitud frente a ella, otra articulación entre ésta y las tareas del presente -porvenir.» (1997: 14).

4 «Llamo táctica a la acción calculada que determina la ausencia de un lugar propio. Por tanto ninguna limitación de la exterioridad le proporciona una condición de autonomía. La táctica no tiene más lugar que el del otro.» Michel De Certeau (1996: 43).

${ }^{5}$ «Tal vez la palabra, la comunicación, están podridas. Están penetradas completamente por el dinero, y no por accidente, sino por naturaleza. Es necesaria una desviación de la palabra. Crear siempre ha sido una cosa distinta que comunicar. Lo importante será tal vez crear vacuolas de no comunicación, interruptores, para escapar del control» (2005).

\section{Bibliografía}

AGAMBEN, Giorgio. (2006) La comunidad que viene. Valencia: Pre-textos.

BAJ Tín, Mijail. (1997a). Estética de la creación verbal. México: Siglo Veintiuno editores.

BAUMAN, Zigmunt. (2005) La sociedad sitiada. Buenos Aires: Fondo de Cultura Económica.

BAUMAN, Zigmunt. (2007) Amor líquido. Buenos Aires: Fondo de Cultura Económica.

BECK, Ulrich. (1998) La sociedad del riesgo, Barcelona, Paidós.

CASTORIADIS, Cornelius. (1997) Poder, política, autonomía. En Un mundo fragmentado. Buenos Aires: Altamira.

DE CERTEAU, Michel. (1996). La invención de lo cotidiano. 1. artes del hacer. México: Universidad Iberoamericana- Instituto Tecnológico y de Estudios Superiores de Occidente-Ministère des Affaires Étrangères. 
DELEUZE, Gilles. (2005) «CONTROL Y DEVENIR, Entrevista con Toni Negri». En EUPHORION No. Especial Virtual 1. Medellín: Euphorion.

DE SOUSA SANTOS, Boaventura. (2002) «Las tensiones de la modernidad». En Foro social mundial: Porto Alegre, otro mundo es posible. Madrid: El viejo topo.

ESCOBAR, Arturo (2005). Más allá del tercer mundo. Globalización y diferencia. Bogotá: Instituto Colombiano de Antropología e historia / Universidad del Cauca.

FOUCAULT, Michel (1999). Estética, ética y hermenéutica, Buenos Aires: Paidós.

HABERMAS, Jurgen, 2003, «Fundamentalismo y terror» entrevista de Giovanna Borradori en La filosofía en la época del terror, Bogotá, Taurus.

MAFFESOLI, Michel (1993). El conocimiento ordinario. Compendio de sociología. México: Fondo de cultura económica.

MULLER, Pierre (2006). Las Políticas Públicas. Bogotá: Universidad Externado de Colombia.

ZIZEK, slavoj, 2004, Violencia en acto, Buenos Aires, Paidós. 